Research

\title{
The cost of antiretroviral therapy in Haiti
}

Serena P Koenig*1, Cynthia Riviere ${ }^{2}$, Paul Leger ${ }^{2}$, Patrice Severe ${ }^{2}$,

Sidney Atwood ${ }^{1}$, Daniel W Fitzgerald ${ }^{2,3}$, Jean W Pape ${ }^{2,3}$ and

Bruce R Schackman 4

Address: ${ }^{1}$ Division of Social Medicine and Health Inequalities, Brigham and Women's Hospital, Boston, MA 02115, USA, ${ }^{2}$ Groupe Haitien d'Etude du Sarcome de Kaposi et des Infections Opportunistes (GHESKIO) Center, Port-Au-Prince, Haiti, ${ }^{3}$ Department of Medicine, Weill Medical College, Cornell University, New York, NY, 10021, USA and "Department of Public Health, Weill Medical College, Cornell University, New York, NY, 10021, USA

Email: Serena P Koenig* - skoenig@partners.org; Cynthia Riviere - cynthiariviere@yahoo.com; Paul Leger - pauldenisl@gheskio.org; Patrice Severe - psevere@gheskio.org; Sidney Atwood - satwood@partners.org; Daniel W Fitzgerald - dfitzgerald@gheskio.org; Jean W Pape - jwpape@gheskio.org; Bruce R Schackman - brs2006@med.cornell.edu

* Corresponding author

Published: 14 February 2008

Cost Effectiveness and Resource Allocation 2008, 6:3 doi:10.1186/1478-7547-6-3

This article is available from: http://www.resource-allocation.com/content/6/1/3

(C) 2008 Koenig et al; licensee BioMed Central Ltd.

This is an Open Access article distributed under the terms of the Creative Commons Attribution License (http://creativecommons.org/licenses/by/2.0), which permits unrestricted use, distribution, and reproduction in any medium, provided the original work is properly cited.

\section{Abstract}

Background: We determined direct medical costs, overhead costs, societal costs, and personnel requirements for the provision of antiretroviral therapy (ART) to patients with AIDS in Haiti.

Methods: We examined data from 218 treatment-naïve adults who were consecutively initiated on ART at the GHESKIO Center in Port-au-Prince, Haiti between December 23, 2003 and May 20, 2004 and calculated costs and personnel requirements for the first year of ART.

Results: The mean total cost of treatment per patient was \$US 982 including \$US 846 in direct costs, \$US II 4 for overhead, and \$US 22 for societal costs. The direct cost per patient included generic ART medications $\$$ US 355 , lab tests $\$ U S 130$, nutrition $\$$ US 117 , hospitalizations $\$ U S 62$, pre-ART evaluation $\$ U S 58$, labor $\$$ US 5 I, non-ART medications $\$ U S 39$, outside referrals $\$ U S$ $3 \mathrm{I}$, and telephone cards for patient retention \$US 3. Higher treatment costs were associated with hospitalization, change in ART regimen, TB treatment, and survival for one year. We estimate that 1.5 doctors and 2.5 nurses are required to treat 1000 patients in the first year after initiating ART.

Conclusion: Initial ART treatment in Haiti costs approximately \$US I,000 per patient per year. With generic first-line antiretroviral drugs, only $36 \%$ of the cost is for medications. Patients who change regimens are significantly more expensive to treat, highlighting the need for less-expensive second-line drugs. There may be sufficient health care personnel to treat all HIV-infected patients in urban areas of Haiti, but not in rural areas. New models of HIV care are needed for rural areas using assistant medical officers and community health workers. 


\section{Background}

Annual expenditures on HIV/AIDS interventions in resource-poor countries have increased 30-fold over the last ten years, to an estimated \$US 10 billion in the 2007 [1]. As HIV/AIDS services are rapidly scaled up, determining the cost of specific HIV/AIDS interventions is critical in order to evaluate their cost-effectiveness, set program priorities, and budget for further scale-up [2]. Antiretroviral therapy (ART) is extremely effective in resource-poor settings, increasing survival for patients with AIDS from $30 \%$ to $90 \%$ at one-year [3-7]. However, the only studies reporting data on the costs of providing ART in resourcepoor settings derived from actual patient experience come from South Africa, Thailand, and Mexico [8-11]. Few studies have been conducted in the least developed countries [12-14] and none of these studies collected patient-level data. Cost data are a necessary prerequisite to evaluating the cost-effectiveness of HIV treatment in these severely resource-constrained settings, which account for the greatest share of the global burden of HIV disease.

In the current study, we determine direct medical costs, overhead costs, societal costs, and personnel requirements for providing ART to patients with AIDS in Haiti. Haiti is the poorest country in the Western Hemisphere, on par with the least developed countries in sub-Saharan Africa, with a per capita income of \$US 380/year and per capita health expenditure of \$US 8/year [15]. The prevalence of HIV in Haiti is currently estimated at approximately $3.8 \%$ in the adult population, about half that of sub-Saharan Africa, which has a regional prevalence of 5.9\%, ranging from 3.7\% in Angola to 33\% in Swaziland $[16,17]$. In March 2003, the Global Fund to Fight AIDS, Tuberculosis, and Malaria (GFATM) granted funding to Haiti to provide comprehensive HIV/AIDS care which allowed GHESKIO to begin enrolling large numbers of patients on ART. The United States President's Emergency Plan for AIDS Relief (PEPFAR) provided additional support for the project in January 2004. Previous reports from Haiti have documented that ART is effective [4,6]. This report details the cost and personnel requirements of providing ART during the first year of therapy.

\section{Methods \\ Study setting}

The Haitian Study Group for Kaposi's Sarcoma and Opportunistic Infections (GHESKIO) was formed in 1982 by a group of Haitian health professionals who described the first cases of AIDS in a developing country [18]. The mission of GHESKIO is to provide clinical services and training, and to conduct research on HIV/AIDS. The clinic is located in downtown Port-au-Prince; the majority of patients are urban residents who make less than US\$ 1 per day. The clinic at GHESKIO has provided free HIV counseling, testing, care, and prevention services since 1983.
Beginning in March 2003, the clinic began providing ART free-of-charge to all patients with AIDS.

All patients presenting to GHESKIO receive HIV voluntary counseling and testing and screening for other sexually transmitted diseases. All patients with cough undergo evaluation for tuberculosis (TB). HIV-infected patients have a history and physical examination by a physician and a CD4 cell count is measured. Patients with an AIDSdefining illness or a CD4 cell count $<200$ cells/ml are started on ART. Prior to starting ART, a complete blood count, renal function tests and liver enzyme tests are performed, and patients meet with a social worker for ART counseling and education.

In the GHESKIO ART treatment protocol, patients on ART are to be seen in the clinic weekly for the first two months of therapy and then monthly thereafter. At each visit, patients are seen by a clinician (physician or nurse), and by a pharmacist who dispenses ART and provides adherence counseling. At three-month intervals, the patients are to be seen by a social worker for additional counseling. Laboratory monitoring includes CD4 cell counts, liver function tests, renal and glucose tests, and complete blood counts every six months. If an opportunistic infection is suspected, appropriate laboratory testing is performed.

Patients are referred to on-site sexually transmitted infection (STI) and family planning clinics when clinically indicated. TB medications are prescribed in the ART clinic and dispensed by a nurse in the adjoining GHESKIO TB clinic. Patients requiring inpatient care are referred to one of several nearby hospitals in Port-au-Prince. When subspecialty care is required (ophthalmology, dermatology, etc), patients are referred to private providers affiliated with GHESKIO. Patients with wasting or economic need receive nutritional supplementation free-of-charge on site once per month. All patients receive pre-paid telephone cards and transportation subsidies to facilitate retention in the program. Clinic staff give the patients pre-paid telephone cards to enhance adherence to medications and clinic visits; with the cards, the patients can call the clinic staff free-of-charge.

\section{Health services utilization}

We determined actual health care services utilization of consecutively enrolled treatment-naïve adult AIDS patients who initiated ART at the GHESKIO clinic from December 23, 2003 to May 20, 2004. We measured service utilization and cost from the societal perspective, and included all costs that were actually incurred in the month prior to ART initiation, and for 365 days afterwards. We collected data from electronic medical records and from patient charts. For each clinic visit, we extracted: weight; 
symptoms; active medical conditions; laboratory and radiographic tests conducted; ART medications and number of pills dispensed; medications for TB, opportunistic infections, and other conditions; nutritional support; type of provider seen; referrals to specialty care; and hospitalization.

Cost estimates were obtained using the micro-costing approach outlined by Drummond et al. [19] in which each component of health care that is utilized (such as medications and laboratory tests) is recorded and a unit cost is applied to each component. Costs were measured in 2004 United States dollars. The cost of ART drugs, antibiotics, and other medications stocked in the GHESKIO pharmacy were provided by GHESKIO. For TB and reproductive health medications provided free-of-charge through the Haitian Ministry of Health, we used the prices listed by the International Dispensary Association, a nonprofit supplier of generic medications to Haiti. The costs of medications not available at the GHESKIO clinic were obtained from a survey of six private pharmacies in Portau-Prince. The cost of laboratory tests (including CD4 cell counts) that were conducted on-site were obtained from internal GHESKIO accounting. Chest radiographs were conducted off-site; we used the price that GHESKIO paid for each X-ray. Nutrition costs were provided by the nongovernmental organization that provides food supplements to the GHESKIO clinic, and pre-paid telephone card costs were the price paid for them by GHESKIO. For cost of hospitalizations, a panel of GHESKIO clinicians (PL, PS, DWF, and JWP) estimated services utilized on a case-by-case basis; we estimated the amount paid for the day of admission and for subsequent days in care. To estimate the cost of each laboratory test, medication, and radiographic study that was conducted in the hospital, we used the GHESKIO cost to deliver these services. For specialty care, we surveyed specialty physicians in Port-auPrince to determine the amounts paid for services by these outside providers; we used charges as they were consistent with the labor and administrative costs of comparable visits to GHESKIO physicians.

To determine medical personnel utilization and direct labor costs in the ART clinic, we conducted an observational study of eight physicians and five nurses to estimate the average amount of time per visit. Seventy-seven physician visits and 48 nursing visits were observed by a member of the study team, who recorded the number of minutes each patient spent in the room with each provider. To limit observational bias, measurements were conducted from the waiting room at unannounced dates and times. We found that on average physicians spent 15 minutes and nurses spent 18 minutes with each patient. We interviewed the TB clinic staff to estimate the time spent by the TB nurse to dispense medications and pro- vide adherence counseling (10 minutes per patient). To estimate the indirect labor cost (for patient care activities such as recording patient data), we added an additional $50 \%$ to the time devoted to face-to-face medical care (i.e. 30 seconds indirect time for each minute of face-to-face time) based on provider estimates. We then used the GHESKIO average salary by provider type to determine the cost of labor per patient based on a provider work schedule of 200 eight-hour days per year.

Overhead costs were allocated to each visit from actual expenditures based on clinic patient volume (adjusted for the duration of patient visits) except for electricity and cleaning supply costs, which were allocated based on square footage. Capital costs were annualized and discounted at a rate of 5\%. These expenditures had been documented in financial reports to the GFATM. Societal costs included non-medical costs (transportation and time) incurred by the patient. The value of patient time was calculated based on the average wage rate per day reported by GHESKIO patients, and transportation costs were calculated according to the patient's residence zone using a weighted average based on the social worker's estimation of the percentage of patients who used each type of transportation (walking, public transportation or private taxi) and its cost (in the case of public transportation or taxi) for patients arriving from each of 16 Port-au-Prince residence zones.

\section{Analysis}

Data were entered into an Access database (Microsoft, Redmond, WA) and then converted to SAS Version 9.1 (SAS, Carey NC) for analysis. The primary outcome was cost of treatment. Direct costs were presented as mean and median costs with interquartile ranges (see Tables 1 and 2 ). Secondary outcomes included physician time and nursing time spent caring for patients. For both primary and secondary outcomes, we conducted univariate and multivariate analyses using the following variables: CD4 cell count (measured as a continuous variable), number of symptoms at treatment initiation, clinical CDC stage $(\mathrm{A}, \mathrm{B}, \mathrm{C})$, education (measured as none, primary, secondary, or university), income (in five pre-defined income categories), baseline weight (in quartiles), and age greater than median, baseline hemoglobin $<10 \mathrm{mg} / \mathrm{dl}$, mortality, hospitalization, TB treatment, change in regimen, and gender (all measured as binary variables). To examine the impact of early death and loss to follow-up, we repeated these analyses for only the patients who remained in care for the entire year. The arithmetic and geometric means of the total cost and labor (physician time and nurse time) were not normally distributed. Therefore, we conducted the analyses with a generalized linear model (GLM) with a gamma log link [20]. Variables were maintained in the multivariate GLM models for $\mathrm{p}<0.05$. GLM results are 
Table I: Direct treatment utilization and costs for the total cohort $(n=218)$

\begin{tabular}{|c|c|c|c|c|}
\hline & $\begin{array}{l}\text { Mean utilization per } \\
\text { patient for the Ist } \\
\text { year of ART }\end{array}$ & $\begin{array}{l}\text { Median utilization (IQ } \\
\text { range) per patient for } \\
\text { the }\left.\right|^{\text {st }} \text { year of ART }\end{array}$ & $\begin{array}{l}\text { Mean cost per } \\
\text { patient for the Ist } \\
\text { year of ART (\$US) }\end{array}$ & $\begin{array}{l}\text { Median cost (IQ range) } \\
\text { per patient for the I st } \\
\text { year of ART (\$US) }\end{array}$ \\
\hline $\begin{array}{l}\text { Pre-ART work-up (labor and } \\
\text { laboratory studies) }\end{array}$ & $*$ & $*$ & 58 & $6 I(6 I$ to 61$)$ \\
\hline Labor cost (\# of ART visits) & 12.6 & $14(1 \mid$ to 16$)$ & 51 & $5 \mathrm{I}(42$ to 61$)$ \\
\hline CD4 cell counts** (\# of tests) & 1.1 & I (I to I) & 32 & $30(30$ to 30$)$ \\
\hline ART monitoring labs (\# of tests) & 9.5 & II (6 to I2) & 72 & 81 (46 to 92$)$ \\
\hline TB tests (\# of tests) & 1.7 & $0(0$ to 3$)$ & 8 & $0(0$ to 14$)$ \\
\hline Other laboratory tests (\# of tests) & 2.7 & 2 (I to 3$)$ & 8 & $5(0$ to 13$)$ \\
\hline Chest radiographs (\# of $x$-rays) & 0.4 & $(0$ to $\mathrm{I})$ & 10 & $0(0$ to 24$)$ \\
\hline $\begin{array}{l}\text { Anti-retroviral therapy (\# of days } \\
\text { on ART) }\end{array}$ & 291 & $362(24$ I to 375$)$ & 355 & 282 (225 to 583$)$ \\
\hline $\begin{array}{l}\text { TB medications (\# of days on } \\
\text { therapy) }\end{array}$ & 19 & $0(0$ to 0$)$ & 6 & $0(0$ to 0$)$ \\
\hline Other medications ${ }^{* * *}$ & $*$ & $*$ & 33 & $28(15$ to 40$)$ \\
\hline Outside referrals & 0.3 & $0(0$ to 0$)$ & 31 & $0(0$ to 0$)$ \\
\hline Hospitalizations & 0.1 & $0(0$ to 0$)$ & 62 & $0(0$ to 0$)$ \\
\hline Telephone cards & 2.4 & $2.4(\mathrm{I}$ to 3$)$ & 3 & $3(1$ to 4$)$ \\
\hline Nutritional support & $*$ & * & 117 & $140(0$ to 180$)$ \\
\hline Total (\# of days in care) & 299 & 365 (357 to 365$)$ & 846 & 846 (654 to 1075$)$ \\
\hline
\end{tabular}

IQ range $=$ interquartile range

$*$ No utilization units defined.

** This does not include the baseline CD4 cell count done before the initiation of ART; also, many patients had a I2-month CD4 cell count that was done more than 365 days after ART initiation, and was therefore excluded from the analysis.

*** GHESKIO paid a mean cost of \$US 33.69 per patient for other medications (i.e. not including ART or TB drugs). The mean cost per patient for medications purchased outside of GHESKIO was \$US 4.3I (median cost of \$US I.23).

reported as relative differences, representing the ratio of the cost, physician time, or nurse time in the presence of each dichotomized variable (e.g. hospitalization) compared to this value in the absence of each of these variables (e.g. no hospitalization). There were no sets of variables in the reported model that showed signs of unacceptable collinearity.

\section{Results}

\section{Study population}

Between December 23, 2003 and May 20, 2004, 220 treatment-naïve adult AIDS patients initiated ART at the GHESKIO clinic. We reviewed the medical records of 218 $(99 \%)$ of these patients; we were not able to find two records. The baseline characteristics of the 218 study patients are provided in Table 3 . Of the 218 patients initiated on ART, 169 (78\%) remained in care for one year, 35 $(16 \%)$ died after a mean time in care of 68 days, and 14 $(6 \%)$ were lost to follow-up after a mean time in care of 98 days. A total of 20 patients $(9 \%)$ were hospitalized during the study period, and $27(12 \%)$ had a change in ART regimen due to side effects or treatment failure.

\section{Cost of ART treatment}

The mean total cost of treatment per patient was \$US 982, including \$US 846 in direct costs, \$US 114 for overhead, and \$US 22 for societal costs. For patients who remained in care for one year, the mean total cost of treatment per patient was \$US 1132 . Table 1 presents the mean, median, and interquartile ranges of direct costs for all patients in the cohort; Table 2 presents these values for patients who remained in care for one year.

The mean direct cost per patient included: \$US 355 for ART; \$US 130 for laboratory testing and radiographs; \$US 117 for food supplementation; \$US 62 for hospitalization; \$US 58 for screening evaluation before ART was initiated; \$US 51 for labor; \$US 39 for non-ART medications; \$US 31 for referrals to specialty care outside of the GHESKIO clinic; and \$US 3 for telephone cards (Table 1). For patients who remained in care for one year, the mean direct cost was \$US 972 (Table 2).

The mean overhead costs were \$US 114 per patient; the largest components (Table 4) were indirect clinical costs (\$US 26), non-direct health care professional labor (\$US 24), monitoring and evaluation (\$US 19), electricity (\$US 15 ), and maintenance (\$US 15). Mean societal costs were \$US 22 per patient. For patients who remained in care for one year, mean overhead costs were \$US 135 and mean societal costs were \$US 27. 
Table 2: Direct treatment utilization and costs for patients that remained in care for one full year $(n=169)$

\begin{tabular}{|c|c|c|c|c|}
\hline & $\begin{array}{l}\text { Mean utilization } \\
\text { per patient for the } \\
\text { | st year of ART }\end{array}$ & $\begin{array}{l}\text { Median utilization (IQ } \\
\text { range) per patient for } \\
\text { the I st year of ART }\end{array}$ & $\begin{array}{c}\text { Mean cost per } \\
\text { patient for the }\left.\right|^{\text {st }} \\
\text { year of ART (\$US) }\end{array}$ & $\begin{array}{c}\text { Median cost (IQ range) } \\
\text { per patient for the Ist } \\
\text { year of ART (\$US) }\end{array}$ \\
\hline $\begin{array}{l}\text { Pre-ART workup (labor and } \\
\text { laboratory studies) }\end{array}$ & $*$ & $*$ & 58 & $6 I(6 I$ to $6 I)$ \\
\hline Labor cost (\# of ART visits) & 14.9 & $15(14$ to 16$)$ & 59 & $54(47$ to 63$)$ \\
\hline CD4 cell counts** (\# of tests) & 1.3 & I (I to 2$)$ & 39 & 30 (30 to 60$)$ \\
\hline ART monitoring labs (\# of tests) & 11.3 & II (9 to 13) & 85 & 85 (68 to 99$)$ \\
\hline TB tests (\# of tests) & 1.8 & $0(0$ to 3$)$ & 8 & $0(0$ to 14$)$ \\
\hline Other laboratory tests (\# of tests) & 3.2 & $2(1$ to 4$)$ & 9 & 8 (2 to 13$)$ \\
\hline Chest radiographs (\# of $x$-rays) & 0.4 & $0(0$ to 1$)$ & 10 & $0(0$ to 24$)$ \\
\hline $\begin{array}{l}\text { Anti-retroviral therapy (\# of days on } \\
\text { ART) }\end{array}$ & 357 & 367 (355 to 379$)$ & 439 & $413(273$ to 601$)$ \\
\hline TB medications (\# of days on therapy) & 21 & $0(0$ to 0$)$ & 6 & $0(0$ to 0$)$ \\
\hline Other medications ${ }^{* * *}$ & $*$ & $*$ & 37 & 31 (2I to 42$)$ \\
\hline Outside referrals & 0.4 & $0(0$ to 0$)$ & 39 & $0(0$ to 19$)$ \\
\hline Hospitalizations & 0.05 & $0(0$ to 0$)$ & 35 & $0(0$ to 0$)$ \\
\hline Telephone cards & 2.4 & $3.2(2$ to 3$)$ & 3 & $4(3$ to 4$)$ \\
\hline Nutritional support & $*$ & * & 145 & $160(100$ to 200$)$ \\
\hline Total (\# of days in care) & 364 & 365 (365 to 365$)$ & 972 & 923 (770 to 1098$)$ \\
\hline
\end{tabular}

$\mathrm{IQ}$ range $=$ interquartile range

* No utilization units defined.

** This does not include the baseline CD4 cell count done before the initiation of ART; also, many patients had a I2-month CD4 cell count that was done more than 365 days after ART initiation, and was therefore excluded from the analysis.

*** GHESKIO paid a mean cost of US\$33.69 per patient for other medications (i.e. not including ART or TB drugs). The mean cost per patient for medications purchased outside of GHESKIO was \$US 4.3I (median cost of \$US I.23).

\section{Predictors of cost: Full cohort}

In univariate analyses, predictors of higher treatment cost included hospitalization (\$US 1406 vs. \$US 939), change in ART regimen due to side effects or treatment failure (\$US 1308 vs. \$US 936), fewer than five symptoms at ART initiation (\$US 1044 vs. \$US 853), higher body weight at baseline (\$US 1031 vs. \$US 825), and survival for one year (Table 5). Patients with high body weight and few symptoms at ART initiation were more likely to survive and remain in care for a full year. Total costs were significantly higher for patients who remained in care (\$US 1132) compared with those who died (\$US 508) or were lost to follow-up (\$US 382), due to additional days of treatment. Cost per day in care was significantly higher for patients who died; they had a higher rate of hospitalization $(29 \%$ vs. $6 \%)$ and their cost per day in care was approximately twice as high ( $\$ 7.47$ per day) as those who remained in care for one year ( $\$ 3.10$ per day) or were lost to follow-up (\$3.90 per day).

In multivariate analyses, hospitalization, a change in ART regimen, TB treatment, and survival for one year were significantly predictive of higher treatment costs (Table 6). Survival was associated with higher total treatment costs because these patients remained in care and used services for an entire year.

\section{Predictors of cost: Patients who remained in care for one year}

In univariate analyses of patients who remained in care for one year, higher costs were associated with hospitalization (\$US 1955 vs. \$US 1092), a change in ART regimen due to side effects (\$US 1469 vs. \$US 1085), TB treatment (\$US 1336 vs. \$US 1105), and CDC Stage C AIDS symptoms at ART initiation (\$US 1194 vs. \$US 1048) (Table 7). In multivariate analysis, hospitalization, change in ART regimen, and older age were associated with significantly higher treatment costs (Table 8).

\section{Medical personnel utilization}

The mean total physician labor time per patient was 2.4 hours, and total nurse labor time per patient was 4.0 hours, including the time of the TB clinic nurse. Assuming 1600 hours per year available for patient care by each doctor or nurse, this implies that 1.5 doctors and 2.5 nurses are required to treat 1000 patients in the first year after initiating ART.

In univariate analyses of the total cohort, both physicians and nurses spent more time with patients with $\mathrm{TB}$, and with those who survived (Table 5). Physicians also devoted significantly more time to patients with a change in ART regimen, no income, and female gender. Patients 
Table 3: Baseline characteristics of patients receiving ART (n = 218)

\begin{tabular}{|c|c|}
\hline Female sex - no. (\%) & $122(56)$ \\
\hline \multicolumn{2}{|l|}{ Age - no. (\%) } \\
\hline I. $<20 \mathrm{yr}$ & $2(2)$ \\
\hline 2. $20-29 \mathrm{yr}$ & $25(12)$ \\
\hline 3. $30-39 \mathrm{yr}$ & $83(38)$ \\
\hline 4. $40-49 \mathrm{yr}$ & $74(34)$ \\
\hline 5. $>49 \mathrm{yr}$ & $31(14)$ \\
\hline Resident of Port-au-Prince - no. (\%) & $191(88)$ \\
\hline Income < \$US I/day - no. (\%) & $148(68)$ \\
\hline \multicolumn{2}{|l|}{ Education - no. (\%) } \\
\hline I. None & $49(22)$ \\
\hline 2. Primary school & $67(3 \mathrm{I})$ \\
\hline 3. Secondary school & $94(43)$ \\
\hline 4. College & $8(4)$ \\
\hline
\end{tabular}

Marital status - (\%)

I. Common-law marriage $65(30)$

2. Married 37 (17)

3. Separated $54(25)$

4. Single 31 (17)

5. Widowed 26 (12)

AIDS-defining illness (CDC Stage C) - no. (\%)

|4| (65)

Body weight - kg

I. Men
a) Median
55.5
b) Interquartile range
49.1 to 61.4
2. Women
a) Median
48.4
b) Interquartile range
42.7 to 55.5

CD4 cell count $/ \mathrm{mm}^{3}$

I. Median

108

2. Interquartile range

40 to 180

CD4 cell count $<50 / \mathrm{mm}^{3}-$ no. (\%)

$61(30)$

Initial antiretroviral-therapy regimen - no. (\%)

I. Nevirapine, zidovudine, lamivudine

III (5I)

2. Other nevirapine-based regimen

3. Efavirenz, zidovudine, lamivudine

$5(2)$

4. Other efavirenz-based regimen

$92(42)$

$10(5)$

who died consumed more physician time per day in care (1.2 minutes per day in care) than those who were lost to follow up ( 0.8 minutes per day in care) or those who remained in treatment for the first year $(0.5$ minutes per day in care). For nurses, there was little difference in time per day in care among these patient groups. Nurses spent 1.4 minutes per day in care for patients who died, 1.2 minutes for those who were lost to follow-up, and 1.3 minutes for those who remained in care for the year.

In the multivariate analysis of the total cohort, survival and TB treatment were associated with greater physician and nursing time, and a change in ART regimen, hospitalization, and female gender were associated with more physician time (Table 6). In the multivariate analysis of those who remained in care for the whole year, TB treatment was associated with increased physician and nursing time, and patients who changed ART regimen and those who were anemic required more physician time (Table 8).

\section{Discussion}

We determined health care utilization, cost, and human resource requirements for the first year of ART in a cohort of adult AIDS patients consecutively enrolled in an urban clinic in Port-au-Prince, Haiti. HIV/AIDS can be effectively treated in Haiti for approximately US $\$ 1000$ per patient per year.

The cost of ART medications comprised only $36 \%$ of the total expenditures and is not the only driver of cost. In Haiti, patients received generic medications at an average cost of \$US 1.22 per day for a three-drug antiretroviral regimen. This is similar to a recent study from South Africa, which reported ART costs of \$US 1.25 per day, with ART consuming $23 \%$ of the budget [10]. These findings are in stark contrast to published figures from countries where generic antiretroviral medications are not routinely used [21]. In a study conducted in the United States, ART medications accounted for $73 \%$ of lifetime medical costs [22]. In a study conducted in Mexico, ART brand named drugs comprised $85 \%$ of the total treatment cost for the first year on therapy [9].

A change in ART regimen due to side effects or treatment failure was associated with significantly higher treatment costs due to the high cost of providing a second-line regimen. Many second-line drugs are not available in generic formulations. For example, the second-line ART drugs lopinavir/ritonavir and abacavir cost \$US 2 and \$US 3 per day each. Furthermore, medication changes required additional physician time. This highlights the need for less-toxic first-line regimens and less-expensive generic second-line drugs for resource-poor settings.

Laboratory tests for the early detection of drug toxicities and for monitoring response to therapy consumed approximately $15 \%$ of the total cost; however, the utility of these lab tests is not certain. A recent study conducted in Thailand investigated the necessity for laboratory toxicity monitoring of ART and concluded that just two lab tests, an ALT and hemoglobin, could prevent most serious short-term toxicity [23]. If this study is confirmed, then 
Table 4: Indirect ART clinic costs, overhead, and societal costs (\$US)

\begin{tabular}{|c|c|c|}
\hline & $\begin{array}{c}\text { Mean cost per patient for total cohort for } \\
\text { | } \text { | }^{\text {st }} \text { year ART (\$US) }\end{array}$ & $\begin{array}{c}\text { Mean cost per patient in care for one } \\
\text { year (\$US) }\end{array}$ \\
\hline \multicolumn{3}{|l|}{ Indirect ART clinic-related costs } \\
\hline $\begin{array}{l}\text { Transportation and storage of medications, } \\
\text { equipment, and supplies }\end{array}$ & 8 & 9 \\
\hline ART clinic computers and furniture & 18 & 21 \\
\hline \multicolumn{3}{|l|}{ Overhead costs } \\
\hline Monitoring and evaluation & 19 & 22 \\
\hline $\begin{array}{l}\text { Non-direct patient care time for health care } \\
\text { professionals }\end{array}$ & 24 & 28 \\
\hline Labor for administrative staff & 3 & 4 \\
\hline Electricity & 15 & 18 \\
\hline Maintenance & 15 & 18 \\
\hline Phone and communication & 3 & 4 \\
\hline Office supplies & 5 & 6 \\
\hline Cleaning supplies & 3 & 4 \\
\hline Security & 1 & 1 \\
\hline Total indirect and overhead costs & 114 & 135 \\
\hline \multicolumn{3}{|l|}{ Societal costs } \\
\hline Transportation to and from GHESKIO* & 16 & 19 \\
\hline Patient Time at GHESKIO & 5 & 6 \\
\hline $\begin{array}{l}\text { Societal costs for outside referrals } \\
\text { (transportation and patient waiting time) }\end{array}$ & 0.5 & 1 \\
\hline $\begin{array}{l}\text { Societal costs for hospitalization } \\
\text { (transportation and waiting time for patients } \\
\text { and family members, and cost of death in the } \\
\text { hospital) }\end{array}$ & 0.5 & 1 \\
\hline Total societal costs & 22 & 27 \\
\hline
\end{tabular}

*GHESKIO subsidized transportation fees for all patients (\$US 0.60 per ART visit; mean subsidy per patient \$US 7.56 per year).

laboratory monitoring of toxicities could be simplified and resources saved. Monitoring for treatment failure is necessary to prevent individual patient morbidity and mortality, and to prevent emergence of drug-resistant virus strains. However, a study conducted in Canada sug- gests that CD4 cell criteria are neither sensitive nor specific in predicting which patients have failed to achieve virologic suppression [24]. In contrast, a study conducted in Africa suggests that inexpensive ELISA based p-24 antigen assays may be very predictive of virologic failure [25].

Table 5: Univariate models of cost and medical personnel utilization per patient in the total cohort $(n=218)$

\begin{tabular}{|c|c|c|c|}
\hline Treatment cost & Relative difference & $95 \% \mathrm{Cl}$ & p-value \\
\hline Survived during observation period $(n=183)$ & 2.11 & $(1.7 I, 2.6 I)$ & $<0.0001$ \\
\hline Hospitalized during ART $(n=20)$ & 1.50 & $(1.13,2.01)$ & 0.0052 \\
\hline ART changed due to side effects $(n=27)$ & 1.40 & $(1.09,1.79)$ & 0.0083 \\
\hline Weight above lowest quartile at baseline $(n=155)$ & 1.25 & $(1.03,1.52)$ & 0.0244 \\
\hline Fewer than 5 symptoms at ART initiation $(n=147)$ & 1.22 & $(1.03,1.46)$ & 0.0238 \\
\hline Physician time & Relative difference & $95 \% \mathrm{Cl}$ & p-value \\
\hline ART changed due to side effects or failure $(n=27)$ & 1.62 & $(1.34,1.97)$ & $<0.0001$ \\
\hline Survived during observation period $(n=183)$ & 1.59 & $(2.18,3.78)$ & $<0.0001$ \\
\hline Treated for TB $(n=33)$ & 1.58 & $(1.32,1.88)$ & $<0.0001$ \\
\hline Female gender $(n=122)$ & 1.22 & $(1.07,1.39)$ & 0.0040 \\
\hline No Income $(n=125)$ & 1.20 & $(1.05,1.37)$ & 0.0089 \\
\hline Nurse time & Relative difference & $95 \% \mathrm{Cl}$ & p-value \\
\hline Treated for TB $(n=33)$ & 1.56 & $(1.27,1.90)$ & $<0.0001$ \\
\hline Survived during observation period $(n=183)$ & 2.13 & $(1.68,2.70)$ & $<0.0001$ \\
\hline
\end{tabular}


Table 6: Multivariate models of cost and medical personnel utilization per patient in the total cohort $(n=2$ I8)

\begin{tabular}{|c|c|c|c|}
\hline Treatment cost & Relative difference & $95 \% \mathrm{Cl}$ & p-value \\
\hline Survived during observation period $(n=183)$ & 3.37 & $(2.72,4.17)$ & $<0.0001$ \\
\hline Hospitalized during ART $(n=20)$ & 2.49 & $(1.90,3.25)$ & $<0.0001$ \\
\hline Treated for TB $(n=33)$ & 1.26 & $(1.03,1.54)$ & 0.0275 \\
\hline ART changed due to side effects $(n=27)$ & 1.25 & $(1.00,1.56)$ & 0.0491 \\
\hline Physician time & Relative difference & $95 \% \mathrm{Cl}$ & p-value \\
\hline Survived during observation period $(n=183)$ & 1.97 & $(1.33,2.69)$ & $<0.0001$ \\
\hline Treated for TB $(n=33)$ & 1.54 & $(1.32,1.88)$ & $<0.0001$ \\
\hline ART changed due to side effects or failure $(n=27)$ & 1.30 & $(0.68,1.97)$ & 0.0127 \\
\hline Hospitalized during ART $(n=20)$ & 1.27 & $(1.01,1.62)$ & 0.0492 \\
\hline Female Gender $(n=122)$ & 1.21 & $(1.12,1.50)$ & 0.0005 \\
\hline Nurse time & Relative difference & $95 \% \mathrm{Cl}$ & p-value \\
\hline Survived during observation period $(n=183)$ & 2.13 & $(1.68,2.70)$ & $<0.0001$ \\
\hline Treated for TB $(n=33)$ & 1.56 & $(1.27,1.90)$ & $<0.0001$ \\
\hline
\end{tabular}

Using such a simple and inexpensive test to detect virologic failure could improve the quality of HIV care and reduce cost compared with current recommendations to monitor CD4 cell counts every six months, if these findings are confirmed [26].

Nutritional support accounted for approximately $10 \%$ of the total cost. This expenditure is critical because Haiti suffers from one of the highest rates of food insecurity in the world, with nearly two-thirds of its population undernourished [15,27]. Wasting is the most common cause of death in patients with AIDS in Haiti [6]. Studies suggest that poor nutrition can accelerate HIV disease progression and death, and that nutritional support may be an effective intervention for malnourished HIV-infected patients [28]. Further, we have found that provision of nutritional support improves adherence to ART and retention in ART treatment [4]. Transportation subsidies are also critical. On average, GHESKIO pays half of the transportation cost, and subsidizes the full amount for patients who miss clinic visits for economic reasons.

In Haiti, we found that the cost of care was significantly higher for patients who survived an entire year (\$US 1132) than for patients who died (US\$ 508). This was due to the additional number of days in care, even though those who died had a higher rate of hospitalization, and their cost per day in care was over twice as high as those who remained in care for the full year. Most patients who died on ART did so soon after ART initiation, and access to advanced tertiary medical care was unfortunately extremely limited; the situation is similar in other least developed countries worldwide. This finding differs from results from better-resourced settings, where hospitaliza-

Table 7: Univariate models of cost and medical personnel utilization per patient that remained in care for one full year $(n=169)$

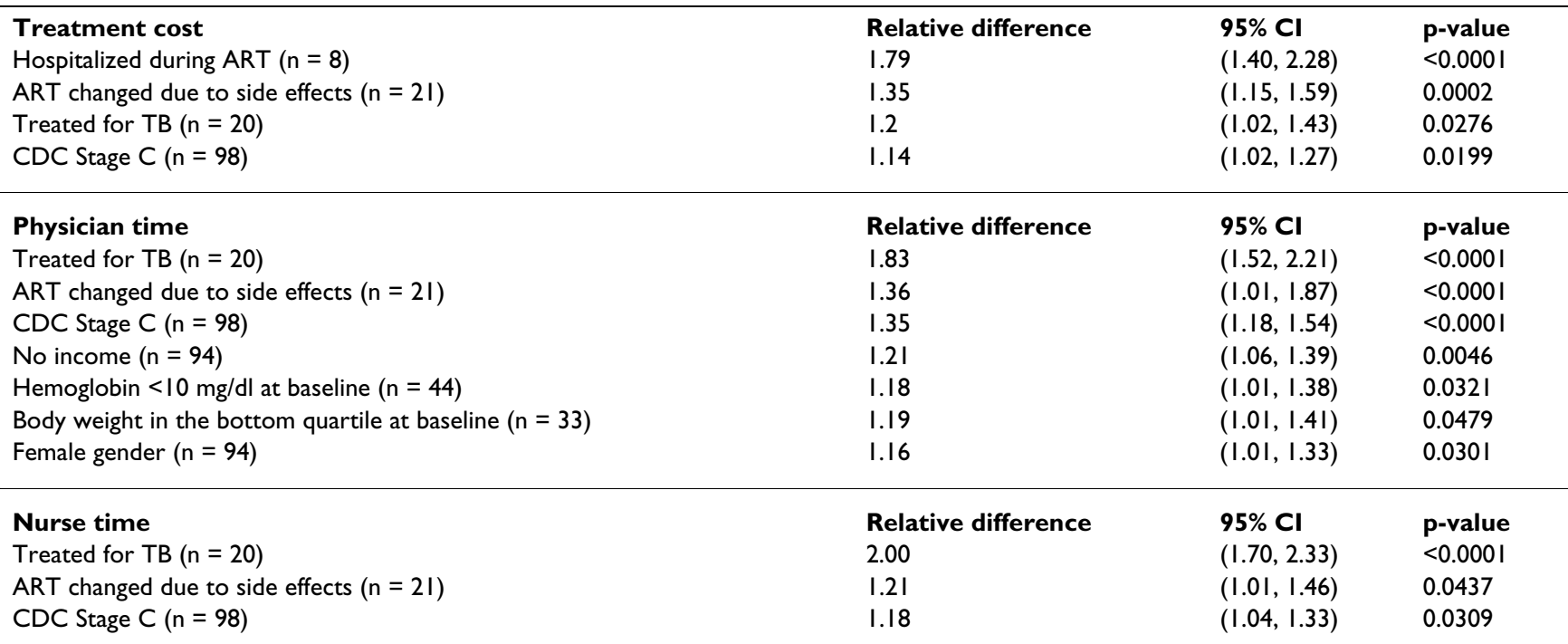


Table 8: Multivariate models of cost and medical personnel utilization per patient that remained in care for one full year $(n=169)$

\begin{tabular}{|c|c|c|c|}
\hline Treatment cost & Relative difference & $95 \% \mathrm{Cl}$ & p-value \\
\hline Hospitalized during ART $(n=8)$ & 1.71 & $(1.34,2.19)$ & $<0.0001$ \\
\hline ART changed due to side effects $(n=2 I)$ & 1.22 & $(1.03,1.45)$ & 0.0176 \\
\hline Age greater than median $(n=84)$ & 1.14 & $(1.03,1.27)$ & 0.0126 \\
\hline Physician time & Relative difference & $95 \% \mathrm{Cl}$ & p-value \\
\hline Treated for TB $(n=20)$ & 1.60 & $(1.28,2.00)$ & $<0.0001$ \\
\hline ART changed due to side effects or failure $(n=21)$ & 1.25 & $(1.01,1.57)$ & 0.0500 \\
\hline Hemoglobin $<10 \mathrm{mg} / \mathrm{dl}(\mathrm{n}=44)$ & 1.22 & $(1.04,1.43)$ & 0.0139 \\
\hline Nurse time & Relative difference & $95 \% \mathrm{Cl}$ & p-value \\
\hline Treated for TB $(n=20)$ & 1.91 & $(1.61,2.26)$ & $<0.0001$ \\
\hline
\end{tabular}

tion, advanced diagnostic tests, intensive care, and medications for extremely ill patients result in high costs during the last months of life $[9,10,29,30]$. Patients in this study had relatively advanced HIV/AIDS, with a median CD4 cell count of 108 at study entry; costs may differ in other settings where patients initiate care with less advanced disease $[21,29,30]$.

The model of ART employed at GHESKIO requires 1.5 physicians and 2.5 nurses to care for 1000 patients. Haiti has approximately 2,000 doctors and most of them are concentrated in urban areas. Therefore, the GHESKIO model may be feasible in the capital city of Port-au-Prince and other urban centers. For example, it is estimated that there are approximately 60,000 HIV-infected people in Port-au-Prince. If half of them required ART, then 45 physicians and 75 nurses would be needed to provide care. However, in rural areas, where there are far fewer physicians and nurses, the GHESKIO model may not be feasible. Models of ART using assistant medical officers, community health care workers, and a limited number of nurses and physicians are needed.

Integration of HIV and TB treatment programs may be a way to conserve limited resources and health professional time. In our cohort, co-treatment of tuberculosis and HIV required only a small increase in cost and physician time compared with treating HIV alone. Others have argued that HIV and TB programs in Africa and other resourcepoor settings have many synergies, and that integration may make both programs more effective $[31,32]$. Reproductive health services can also be integrated into the HIV/ AIDS clinic. We found that female gender was associated with increased physician time because women were more likely to receive reproductive health services, including treatment in the adjoining sexually transmitted infections clinic.

Our study was limited to one clinic in Port-au-Prince. Treatment costs and human resource demands will likely vary from clinic to clinic. Therefore, alternative models of care, especially in rural areas, should be the subjects of future cost and outcomes studies. The costing methodology was limited because we used charges instead of costs for radiographs and specialty care performed outside of GHESKIO, clinician estimates of hospital service utilization, and clinic costs as a proxy for the cost of ancillary services provided in the hospital. However, these limitations are unlikely to have significantly biased our estimates because of the small proportion of total costs represented by hospitalizations and other medical services performed outside of the GHESKIO clinic.

In summary, HIV/AIDS can be treated in Haiti in the first year after initiation of ART for about \$US 1000 per patient. With generic first-line antiretroviral drugs, only $36 \%$ of the cost was for medications. Patients who change regimens are significantly more expensive to treat, highlighting the need for less expensive second-line drugs. This model of ART delivery requires 1.5 physicians and 2.5 nurses to care for 1000 patients. There may be sufficient health care personnel to treat all HIV-infected patients using this model in urban areas of Haiti, but not in rural areas. New models of HIV care for rural areas using assistant medical officers and community health workers are needed. The implications of these findings go beyond Haiti, to the other least developed countries worldwide, where tertiary care is frequently unavailable, health care personnel are scarce in rural areas, and there is a high prevalence of $\mathrm{TB}$. The total resources required to provide care will be considerably higher in high HIV/AIDS prevalence countries of sub-Saharan Africa than in Haiti, and the shortage of qualified health care personnel in these countries will place an even greater burden on the ability to deliver adequate care.

\section{Acknowledgements}

Supported in part by the National Institutes of Health, Fogarty International Center (K0ITW007I42, TW00002, TW000I8, TW006896, and TW00690I) and Institute of Allergy and Infectious Diseases (A 1058257), and by the Frank Hatch Fellowship. Patient care was supported by the Glo- 
bal Fund to Fight AIDS, Tuberculosis and Malaria (GFATM) and the U.S. President's Emergency Plan for AIDS Relief (PEPFAR). The study sponsors had no role in study design, collection, analysis, data interpretation, or decision to submit the paper for publication.

\section{References}

I. Declaration of Commitment on HIVIAIDS: Five Years Later. Report of the Secretary-General, United Nations Assembly, 60th Session. 2006

2. World Health Organization. Progress on Global Access to HIV Antiretroviral Therapy: An update on "3 by 5". Geneva, Switzerland: World Health Organization, 2005. 2005.

3. Coetzee D, Hildebrand K, Boulle A, Maartens G, Louis F, Labatala V, Reuter H, Ntwana N, Goemaere E: Outcomes after two years of providing antiretroviral treatment in Khayelitsha, South Africa. AIDS 2004, I8(6):887-895.

4. Farmer P, Leandre F, Mukherjee JS, Claude M, Nevil P, Smith-Fawzi MC, Koenig SP, Castro A, Becerra MC, Sachs J, Attaran A, Kim JY: Community-based approaches to HIV treatment in resource-poor settings. Lancet 200I, 358(9279):404-409.

5. Laurent C, Diakhate N, Gueye NF, Toure MA, Sow PS, Faye MA Gueye M, Laniece I, Toure Kane C, Liegeois F, Vergne L, Mboup S Badiane S, Ndoye I, Delaporte E: The Senegalese government's highly active antiretroviral therapy initiative: an 18-month follow-up study. Aids 2002, 16(1 0): 1363-1370.

6. Severe P, Leger P, Charles M, Noel F, Bonhomme G, Bois G, George E, Kenel-Pierre S, Wright PF, Gulick R, Johnson WD Jr., Pape JW, Fitzgerald DW: Antiretroviral therapy in a thousand patients with AIDS in Haiti. N Engl J Med 2005, 353(22):2325-2334.

7. Wools-Kaloustian K, Kimaiyo S, Diero L, Siika A, Sidle J, Yiannoutsos CT, Musick B, Einterz R, Fife KH, Tierney WM: Viability and effectiveness of large-scale HIV treatment initiatives in sub-Saharan Africa: experience from western Kenya. AIDS 2006 , 20(I):4I-48

8. Badri M, Maartens G, Mandalia S, Bekker LG, Penrod JR, Platt RW, Wood R, Beck E): Cost-effectiveness of highly active antiretroviral therapy in South Africa. PLoS Med 2006, 3(I):e4.

9. Bautista SA: Costing of HIVIAIDS treatment in Mexico. Bethesda, MD , Partners for Health Reform-plus Project; 2003.

10. Harling G, Wood R: The Evolving Cost of HIV in South Africa: Changes in Health Care Cost With Duration on Antiretroviral Therapy for Public Sector Patients. I Acquir Immune Defic Syndr 2007.

II. Kitajima T, Kobayashi Y, Chaipah W, Sato H, Chadbunchachai W, Thuennadee R: Costs of medical services for patients with HIVI AIDS in Khon Kaen, Thailand. Aids 2003, I 7(16):2375-238I.

12. Kombe G: The human and financial resource requirements for scaling up HIVIAIDS services in Ethiopia. Bethesda, MD , Partners for Health Reform-plus, Abt Associates; 2005.

13. Kombe G, Galaty D, Nwagbara C: Scaling up antiretroviral treatment in the public sector in Nigeria: a comprehensive analysis of resource requirements. Bethesda, MD , Partners for Health Reform-plus, Abt Associates; 2004

14. Kombe G, Smith O: The costs of anti-retroviral treatment in Zambia. Bethesda, MD , Partners for Health Reform-Plus, Abt Associates; 2003.

15. World Bank. Haiti at a Glance. 2005.

16. Ministere de la Sante Publique et de la Population; Institut Haitien de I' Enfance, Centres GHESKIO, and Centers for Disease Control and Prevention. Etude de Sero Surveillance par Methode Sentinelle de la Prevalence du VIH, de la Syphilis, de l'Hepatite B chez les femmes enceintes en Haiti 2003/ 2004. Haiti, 2004. 2004.

17. UNAIDS Report on the Global AIDS Epidemic. 2006

18. Pape JW, Liautaud B, Thomas F, Mathurin JR, St Amand MM, Boncy M, Pean V, Pamphile M, Laroche AC, Johnson WD Jr.: Characteristics of the acquired immunodeficiency syndrome (AIDS) in Haiti. N Engl J Med 1983, 309( (16):945-950.

19. Drummond MF, Sculpher MJ, Torrance GW, O'Brien BJ, Stoddart GL: Methods for the Economic Evaluation of Health Care Programmes. Third edition. Oxford, United Kingdom, Oxford University Press; 2005.

20. Glick R : Economic Evaluation in Clinical Trials. Oxford, Oxford University Press; 2007.
21. Chen RY, Accortt NA, Westfall AO, Mugavero MJ, Raper JL, Cloud GA, Stone BK, Carter J, Call S, Pisu M, Allison J, Saag MS: Distribution of health care expenditures for HIV-infected patients. Clin Infect Dis 2006, 42(7): 1003-1010.

22. Schackman BR, Gebo KA, Walensky RP, Losina E, Muccio T, Sax PE, Weinstein MC, Seage GR 3rd, Moore RD, Freedberg KA: The lifetime cost of current human immunodeficiency virus care in the United States. Med Care 2006, 44(I I):990-997.

23. Nuesch R, Srasuebkul P, Ananworanich J, Ruxrungtham K, Phanuphak $P$, Duncombe C: Monitoring the toxicity of antiretroviral therapy in resource limited settings: a prospective clinical trial cohort in Thailand. J Antimicrob Chemother 2006, 58(3):637-644.

24. Moore D Mermin, J., Awor, A., Yip, B., Hogg, R., Montaner, J.: Performance of Immunologic Responses in Predicting Viral Load Suppression: Implications for Monitoring Patients in Resource-Limited Settings. Journal of Acquired Immune Deficiency Syndromes 2006, 43(4):436-439.

25. Tehe A Maurice, C., Hanson, D.L., Borget, M.Y., Abiola, N., Maran, M., Yavo, D., Tomasik, Z., Boni, J., Schupbach, J., Nkengasong, J.N.: Quantification of HIV-I p24 by a highly improved ELISA: An alternative to HIV-I RNA based treatment monitoring in patients from Abidjan, Cote d'Ivoire. Journal of Clinical Virology 2006, 37(3): 199-205.

26. Antiretroviral Therapy for HIV Infection in Adults and Adolescents in Resource-Limited Settings: Towards Universal Access. Recommendations for a public health approach. Geneva: World Health Organization. 2006.

27. Farmer P: Political violence and public health in Haiti. N Engl J Med 2004, 350( ( 5): | 483-| 486.

28. Mangili A, Murman DH, Zampini AM, Wanke CA: Nutrition and HIV infection: review of weight loss and wasting in the era of highly active antiretroviral therapy from the nutrition for healthy living cohort. Clin Infect Dis 2006, 42(6):836-842.

29. Beck EJ, Miners AH, Tolley K: The cost of HIV treatment and care. A global review. Pharmacoeconomics 200I, 19(1):13-39.

30. Yazdanpanah $Y$, Goldie SJ, Losina E, Weinstein MC, Lebrun T, Paltiel AD, Seage GR 3rd, Leblanc G, Ajana F, Kimmel AD, Zhang H, Salamon $R$, Mouton $Y$, Freedberg KA: Lifetime cost of HIV care in France during the era of highly active antiretroviral therapy. Antivir Ther 2002, 7(4):257-266.

31. Harries AD, Hargreaves NJ, Chimzizi R, Salaniponi FM: Highly active antiretroviral therapy and tuberculosis control in Africa: synergies and potential. Bull World Health Organ 2002, 80(6):464-469.

32. Reid A, Scano F, Getahun H, Williams B, Dye C, Nunn P, De Cock KM, Hankins C, Miller B, Castro KG, Raviglione MC: Towards universal access to HIV prevention, treatment, care, and support: the role of tuberculosis/HIV collaboration. Lancet Infect Dis 2006, 6(8):483-495.
Publish with BioMed Central and every scientist can read your work free of charge

"BioMed Central will be the most significant development for disseminating the results of biomedical research in our lifetime. "

Sir Paul Nurse, Cancer Research UK

Your research papers will be:

- available free of charge to the entire biomedical community

- peer reviewed and published immediately upon acceptance

- cited in PubMed and archived on PubMed Central

- yours - you keep the copyright
BioMedcentral 